\title{
Efficacy of new insecticide molecules against spotted stem borer Chilo partellus (Swinhoe) in maize
}

M. Lavakumar Reddy*, P. Lakshmi Soujanya ${ }^{1}$, J.C. Sekhar ${ }^{1}$, D. Sreelatha and V. Narsimha Reddy Maize Research Centre (PJTSAU), Agricultural Research Institute, Rajendranagar, Hyderabad (Telangana) India ${ }^{1}$ Winter Nursery Centre, ICAR- Indian Institute of Maize Research, Hyderabad (Telangana) India

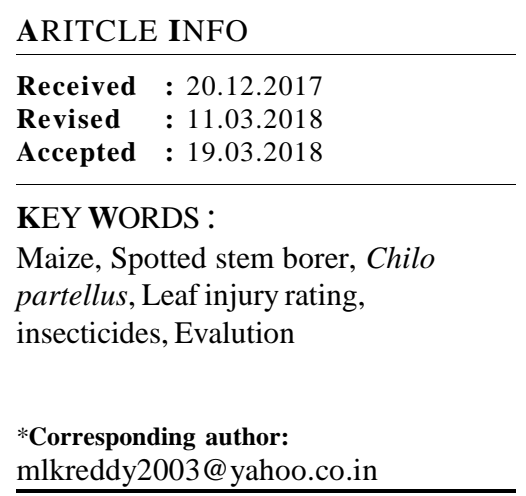

\begin{abstract}
Management of spotted stem borer Chilo partellus (Swinhoe) on maize (DHM 117) by insecticides with different concenterations was conducted at Maize Research Centre, Hyderabad, Telangana during Kharif 2015 and 2016. The observations based on leaf injury rating, grain yield and cost benefit ratio showed that flubendiamide480 SC @ 0.1 $\mathrm{ml}$ followed by flubendiamide 480 SC @ $0.2 \mathrm{ml}$ and deltamethrin 2.8 EC @ $0.8 \mathrm{ml} / \mathrm{l}$ of water proved highly effective and economical in reducing the $C$. partellus damage.

How to view point the article : Reddy, M. Lavakumar, Lakshmi Soujanya, P., Sekhar, J.C., Sreelatha, D. and Reddy, V. Narsimha (2018). Efficacy of new insecticide molecules against spotted stem borer Chilo partellus (Swinhoe) in maize. Internat. J. Plant Protec., 11(1) : 70-72, DOI : 10.15740/HAS/IJPP/11.1/70-72.
\end{abstract}

